\title{
Prevalence of Back Pain among German Ophthalmologists
}

\author{
Thomas Bertelmann $^{\mathrm{a}} \quad$ Astrid Heutelbeck $^{\mathrm{b}}$ Silvia Bopp ${ }^{\mathrm{c}}$ Lise-Lott Sagebiel ${ }^{\mathrm{d}}$ \\ Silke Eichberg ${ }^{\mathrm{e}}$ Ernst Hallier ${ }^{f}$ Reinhard Hilgers ${ }^{g} \quad$ Claudia Quiering $^{\text {h }}$ \\ Hans Hoerauf ${ }^{a}$ \\ ${ }^{a}$ Department of Ophthalmology, University Medical Center Goettingen, Goettingen, Germany; ${ }^{b}$ Department of

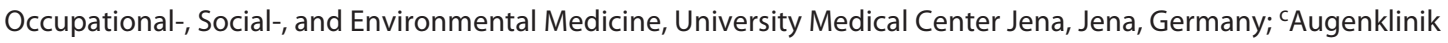 \\ Universitätsallee Bremen, Bremen, Germany; ${ }^{d}$ University Medical Center Schleswig-Holstein, Campus Luebeck, \\ Luebeck, Germany; ${ }^{\text {eDepartment }}$ of Anesthesiology, Spital Affoltern am Albis, Affoltern am Albis, Switzerland; \\ fDepartment of Occupational-, Social-, and Environmental Medicine, University Medical Center Goettingen, \\ Goettingen, Germany; ${ }^{9}$ Department for Medical Statistics, University Medical Center Goettingen, Goettingen,

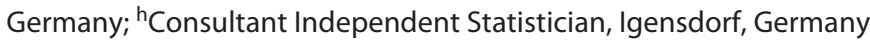

\section{Keywords}

Back pain · Ophthalmologist · Germany · Eye surgery ·

Prevention

\begin{abstract}
Introduction: The aim of this study was to evaluate the prevalence of back pain among German ophthalmologists, to investigate the relationship towards age, gender, various profession-related factors, to correlate localization of pain to subspecialties, and to explore individual therapeutic and coping strategies. Methods: In this prospective, cross-sectional survey, a 9-item questionnaire was sent via mail to all members of the German professional association of ophthalmologists "Berufsverband der Augenärzte Deutschlands e.V. (BVA)." Responses were analyzed according to a pre-specified analysis plan. Results: From a total of 5,954 members contacted, 1,861 copies (31\%) were received back, of which 1,807 (30\%) were suitable for analysis. 913 (51\%) participants were female and 876 (48\%) were male, with a median age of 50 years (interquartile range: $44 ; 57) .1,464$ ophthalmologists
\end{abstract}

karger@karger.com www.karger.com/ore

Karger $\stackrel{\text { ' }}{=}$
(C) 2021 The Author(s)

Published by S. Karger AG, Basel

This is an Open Access article licensed under the Creative Commons Attribution-NonCommercial-4.0 International License (CC BY-NC) (http://www.karger.com/Services/OpenAccessLicense), applicable to the online version of the article only. Usage and distribution for commercial purposes requires written permission.
(81\%) reported current back problems, considerably more than had been reported in the general population or in other medical specialties. Older age, female gender, and higher number of professional years appeared to be risk factors for developing back pain. Overall, neck pain was the leading symptom in 951 attendees (65\%) but differed between ophthalmologists who primarily performed conservative treatment (cervical spine) and those who performed surgery (mainly lumbar spine). 1,037 participants (71\%) link their complaints to their occupational activity. Exercising and back training were reported as common strategies for prevention and coping with the problem. Recommendations for improvement were mainly ergonomic optimization of the working place. Conclusions: The prevalence of back pain complaints in German ophthalmologists is high. Neck pain $(65 \%)$ was the leading localization, followed by low back pain (53\%) and shoulder (38\%) problems, which might emphasize a special back pain complaint profile in ophthalmologists. Low back pain seems to be more common in ophthalmologists with surgical specialization than in those with mainly medical tasks. The high prevalence of back pain in 
ophthalmologists should be communicated with employers, the industry, and professional societies to develop and implement a strategy to prevent occupational-related musculoskeletal disorders and preserve the ability to work and the quality of life.

(c) 2021 The Author(s)

Published by S. Karger AG, Basel

\section{Introduction}

Musculoskeletal disorders (MSDs) remain one of the leading serious health complaints in the general population worldwide. Acute and/or chronic pain of the spinal column, an important subgroup of MSDs, and its possible impact on muscular and/or neurological discomforts of the upper and lower limbs can substantially affect individual experience of pain, capability to work and quality of life [1-3]. The general prevalence of back pain is reported to range between 8 and $65 \%$ annually as well as up to $90 \%$ during lifetime [3-14]. These numbers correlate with data about back pain in Germany with a 12-month prevalence of 16 and $22 \%$, and a lifetime prevalence of 24 and $30 \%$ in men and women, respectively [15]. The prevalence of acute back pain was evaluated to range between 57 and $70 \%$, and chronic complaints of longer than 3 months in $10 \%[15,16]$. Thus, back pain continues to be one of the most common illnesses in the German population [15]. In various subgroups with specific occupational demands like truck drivers, the prevalence can even be higher than the general population [17]. This also seems to be the case for employees working in healthcare like midwives, nurses, and physicians in different medical specialties [1, 18-22].

In developed countries, the overall frequency of cervical and lumbar spine discomfort in the general population has risen by about $25 \%$ within a 10 -year period. The number of people suffering from back pain daily or more than once a week doubled within 1 decade $[13,14]$. Even younger adults between 24 and 35 years of age are distinctly affected [14]. In the general population, males and females equally suffer from back pain. In $70 \%$ of people affected, 1 or more recurrences occur with episodes being longer and described as more intense [14].

Consequently, back pain is the most common cause of chronic inability to work in Germany, and the invalidity number increased from $10 \%$ in the 1950 s to $60 \%$ nowadays. $50 \%$ of early retirements are related to chronic back pain, and its incidence has risen about $211 \%$ within 12 years. Overall direct and indirect costs related to back pain range about 22 billion Euros annually in the Nether- lands $[10,13,14,16,23]$, comparable to medical costs for the treatment of diabetes, depression, heart diseases, or headaches [15].

Approximately $1 / 3$ of the general population relates their back pain complaints to their working conditions [13]. The working environment for ophthalmologists is characterized by specific and nonergonomic occupational motion profile, both for general ophthalmologists (slitlamp examination, refraction, laser-coagulation, and indirect ophthalmoscopy) and for ophthalmic surgeons (using a surgical microscope or magnifying glasses, performing orbital and lid surgery, and conventional retinal detachment surgery) so that a large number of back pain complaints could be expected. Thus, the aim of this study was to evaluate the prevalence and location of back pain among German ophthalmologists, to investigate the relationship toward various profession-related factors, to correlate localization of pain to subspecialties, and to explore individual therapeutic and coping strategies.

\section{Materials and Methods}

In this prospective, cross-sectional evaluation 5,954 ophthalmologists, all members of the German professional association of ophthalmologists "Berufsverband der Augenärzte Deutschlands e.V. (BVA)," were contacted via mail in spring 2009 and asked to complete a standardized questionnaire asking for frequency and location of possible back pain complaints. Members of the BVA were chosen as participants because almost all German ophthalmologists are in this organization. The questionnaire was designed, optimized, and validated by 3 pilot projects in smaller cohorts of ophthalmologists, which have not been published yet. Statistical analysis was performed using Microsoft ${ }^{\circledR}$ Access 2007, Microsoft ${ }^{\circledR}$ Excel 2007, Microsoft ${ }^{\circledR}$, Redmond, WA, USA and Statistica ${ }^{\circledR}$ version 8, StatSoft Europe, Hamburg, Germany.

Qualitative parameters were described using numbers and percentages, quantitative parameters using median and interquartile range (MD and IQR). Statistical analysis was performed using the $\chi^{2}$ test, ANOVA, or Logistic Regression.

\section{Results}

Of a total of 5,954 questionnaires sent to all members of the BVA, 1,861 copies (31\%) were returned. An additional $54(<1 \%)$ had to be excluded due to missing data. Thus, 1,807 questionnaires (30\%) were analyzed. 913 (51\%) participants were female and $876(48 \%)$ were male, respectively (missing data: $18[<1 \%])$. MD (IQR) age was $50(44 ; 57)$ and ranged from 27 to 76 years.

Regarding subspecialization, 266 (15\%) of ophthalmologists specialized in anterior eye segment, 160 (9\%) 
Table 1. Number ( $n$ ) and percentage (\%) of female and male ophthalmologists enrolled in this study with current back pain in various age-groups/compared with rates in age categories from 18 to over 70 years of age [24]

\begin{tabular}{|c|c|c|}
\hline & $\begin{array}{l}\text { Females with current back pain } \\
\text { (ophthalmologists enrolled in } \\
\text { this study/general population [24]), } \\
n(\%) / \%\end{array}$ & $\begin{array}{l}\text { Males with current back pain } \\
\text { (ophthalmologists enrolled in } \\
\text { this study/general population [24]), } \\
n(\%) / \%\end{array}$ \\
\hline $18-29$ years of age & $4(100) / 22$ & $0(0) / 11$ \\
\hline $30-39$ years of age & $78(69) / 23$ & $48(69) / 15$ \\
\hline $40-49$ years of age & $317(86) / 25$ & $232(77) / 16$ \\
\hline $50-59$ years of age & $280(87) / 33$ & $257(79) / 25$ \\
\hline $60-69$ years of age & $83(88) / 29$ & $135(81) / 21$ \\
\hline$>70$ years of age & $5(83) / 31$ & $7(64) / 22$ \\
\hline
\end{tabular}

in strabismus, $78(4 \%)$ in posterior eye segment, and $1,247(69 \%)$ classified themselves as not specialized and working as general ophthalmologists (missing values: 56 [3\%]). Looking at surgical versus nonsurgical (medical) activity, 569 (31\%) ophthalmologists worked exclusively medically, 43 (2\%) surgically, 900 (50\%) medically more than surgically, and 232 (13\%) surgically more than medically (missing values: 63 [3\%]).

The medical histories of back pain revealed that 325 (18\%) ophthalmologists (168 males, 152 females, age 50 $[43 ; 57])(\mathrm{MD}$ [IQR]) reported having had complaints in the past: $146(38 \%)$ of scoliosis, 96 (25\%) Scheuermann's disease, $70(18 \%)$ a lumbar disc prolapse, $27(7 \%)$ a cervical disc prolapse, $18(5 \%)$ a thoracic disc prolapse, $7(2 \%)$ problems with the sacroiliac joint and 25 (6\%) had suffered an earlier trauma.

Current back pain problems were reported by $81 \%$ (1,464 ophthalmologists), 680 males and 769 females, among them 19\% (278) also had a history of previous complaints. Overall, ophthalmologists being older $\{51.5$ (8.4) years (mean [standard deviation])\} with more professional years (22.7 [8.4]) were more affected than younger colleagues (50 [9.3] years; $p=0.0013$ ) with less professional years (21 [9.1]). Furthermore, female participants were younger than males (49.3 [8.4] vs. 51.7 [8.6] years; $p$ $<0.0001$ ) with less surgical activity (6 vs. $15 \%$ ).

Table 1 displays the number of female and male ophthalmologists with current back pain in various agegroups compared with age-matched controls taken from the general population [24]. Overall, female ophthalmologists suffer significantly more from back pain problems in comparison to males $(p=0.0002)$. Apart from gender and age, the number of professional years showed an increased impact on current back pain complaints (Table 2).
Table 2. Prevalence of current back pain complaints dependent on years of professional activity

\begin{tabular}{ll}
\hline Professional years & $\begin{array}{l}\text { Ophthalmologists with } \\
\text { current complaints, } n(\%)\end{array}$ \\
\hline$<10$ years & $67(69)$ \\
$10-20$ years & $455(79)$ \\
$20-30$ years & $551(83)$ \\
$30-45$ years & $346(84)$ \\
\hline
\end{tabular}

Furthermore, all participating ophthalmologists were questioned regarding the location of their current back pain complaints. The results are displayed in Table 3 (multiple answers allowed).

When correlating the location of complaints with the major field of activity (medical vs. surgical), the reported incidence of current back pain was $79 \%$ in ophthalmologists involved in conservative treatment (448), 83\% in those who performed more conservative than surgical treatment (743), 81\% in those who performed more surgical than conservative treatment (187), and 74\% in exclusively surgical ophthalmologists $(32)(p=0.21)$. Whereas the incidences were similar independent from the field of activity, the location of major complaints differed among the groups.

Ophthalmologists with current back pain working strictly medically or medically more than surgically had complaints mainly in the cervical spine area, followed by lumbar spine discomfort and shoulder pain. On the contrary, ophthalmologists working strictly surgically or conservative less than surgically had most of complaints in the lumbar spine region, followed by cervical spine discomfort and shoulder pain (Fig. 1). 
Fig. 1. Location of current back pain stratified by occupational group \{medical $(n=$ $569[31 \%])$, medical $>$ surgical $(n=900$ [50\%]), medical < surgical $(n=232[13 \%])$, surgical $(n=43[2 \%]) ;$ missing values: $(n=$ $63[3 \%])\}$; CS = cervical spine; LS, lumbar spine; $\mathrm{SH}$, shoulder; ULmus, upper limb with muscular complaints; TS, thoracic spine; SIJ, sacroiliac joint; ULneu, upper limb with neurological symptoms; LLmus, lower limb with muscular complaints; LLneu, lower limb with neurological symptoms (multiple answers permitted).

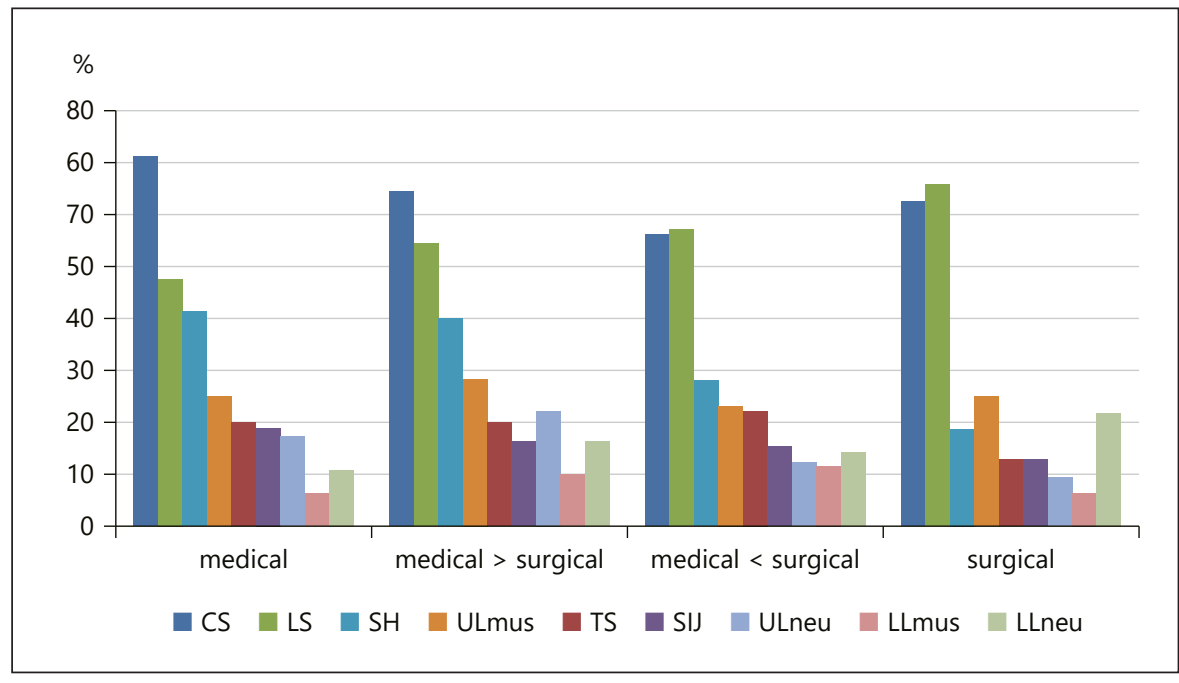

Table 3. Location of current back pain complaints (total number of ophthalmologists with current complaints (percentage) of all participants analyzed; multiple answers permitted)

\begin{tabular}{ll}
\hline Location of discomfort & $\begin{array}{l}\text { Total number of ophthalmologists } \\
\text { with current complaints (percentage) } \\
\text { of all participants analyzed, } n \text { (\%) }\end{array}$ \\
\hline Cervical spine discomfort & $951(65)$ \\
Lumbar spine discomfort & $774(53)$ \\
Shoulder discomfort & $557(38)$ \\
Shoulder discomfort with upper limb involvement and muscle complaints & $384(26)$ \\
Thoracic spine discomfort & $299(20)$ \\
Shoulder discomfort with upper limb involvement and neurologic complaints & $277(19)$ \\
Sacroiliac joint & $251(17)$ \\
Lumbar spine discomfort with lower limb involvement and neurological complaints & $207(14)$ \\
Lumbar spine discomfort with lower limb involvement and muscular complaints & $139(9)$ \\
\hline
\end{tabular}

The analysis of specific activities in the daily practice among ophthalmologists with current back pain revealed that $827(56 \%)$ had problems when working on the slit lamp, 227 (15\%) when performing ophthalmoscopy, 150 (10\%) when working at their desks, 104 (7\%) when performing surgery using a microscope, and 70 (5\%) when measuring the refraction (86 [6\%] missing values).

All attendees with current back pain complaints were asked which therapeutic strategies they use. The results are shown in Table 4.

When asked if the reported back pain problems were thought to be work-related, 1,037 (71\%) of all ophthalmologists affected believe so, $350(24 \%)$ think of a possible correlation and $52(4 \%)$ do not believe in a correlation with work activity (missing values 25 [2\%]). Optimizing the workplace was deemed meaningful by 1,038 (57\%) ophthalmologists. 708 (68\%) participants voted for a
Table 4. Preventive and therapeutic strategies of ophthalmologists with current back pain complaints (multiple answers permitted)

\begin{tabular}{ll}
\hline Coping strategies & $\begin{array}{l}\text { Participants with current } \\
\text { back pain, } n(\%)\end{array}$ \\
\hline Sports/back training & $807(55)$ \\
Massage & $782(53)$ \\
Physiotherapy & $694(47)$ \\
Use of analgesics & $669(46)$ \\
Heat application & $636(43)$ \\
Osteopathy & $205(14)$ \\
Yoga & $158(11)$ \\
Surgical interventions & $85(6)$
\end{tabular}

height-adjustable slit lamp and desk, and 588 (68\%) suggest slit lamp oculars adaptable in height and inclination. Further proposals to improve ergonomic conditions of the workplace were the use of ergonomic chairs and 

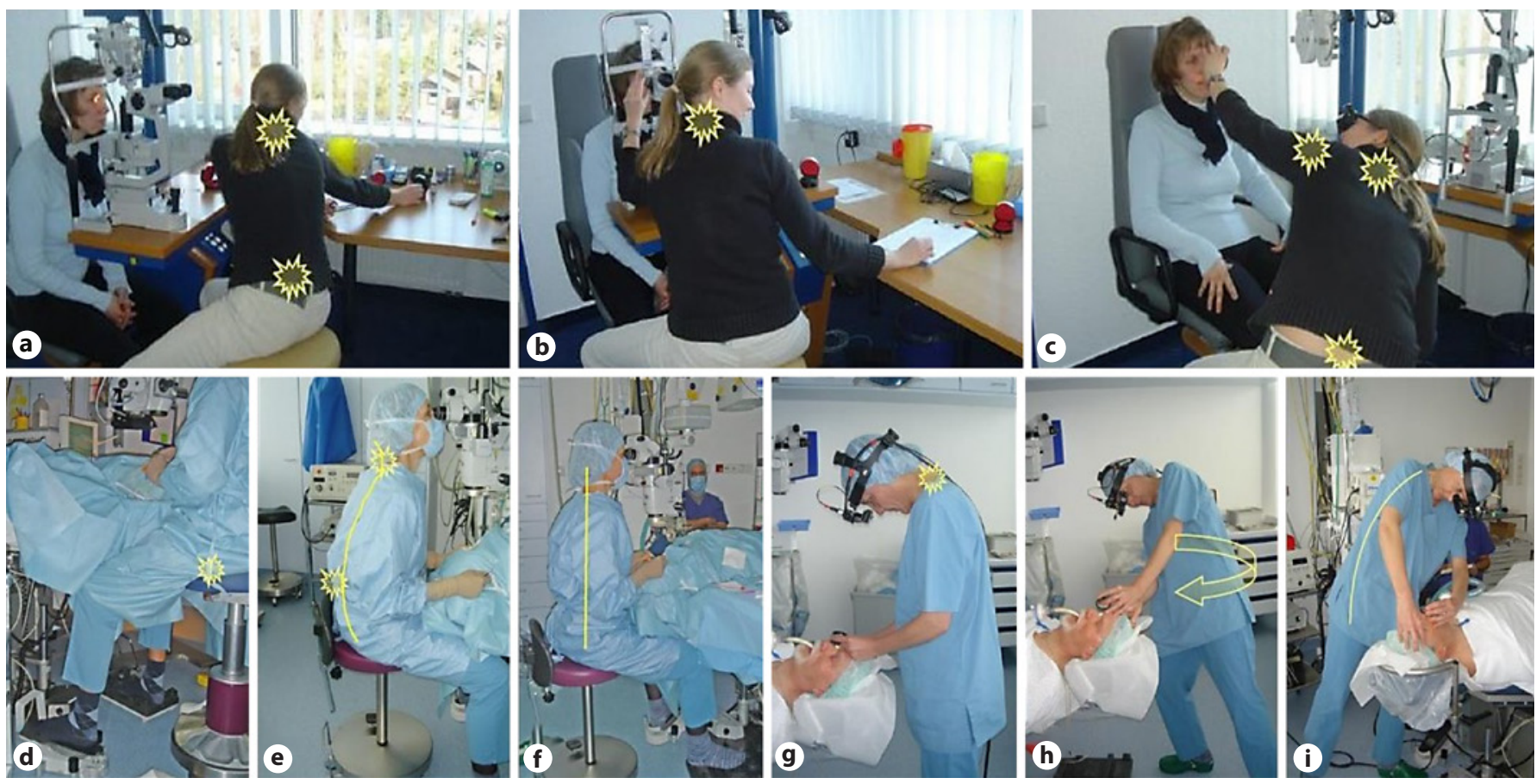

Fig. 2. Occupational positions and motions in a routine clinical setting twisting and bending between slit lamp and desk (a); performing ophthalmoscopy $(\mathbf{b}, \mathbf{c})$; on the operation microscope $(\mathbf{d}-\mathbf{f})$; funduscopy in the operation room $(\mathbf{g}-\mathbf{i})$.

height-adjustable slit lamp-desk units, ophthalmoscopy in supine position, automated phoropters, improved flexibility of the slit lamps with regard to height and angulation of the oculars, improved stability of the patients' head, easier positioning of patients during examination, support for arms/elbows when performing ophthalmoscopy or surgery, optimization of the operation table to allow more space for surgeons' legs.

\section{Discussion}

MSD, in particular when affecting the back and neck and shoulder, may severely impair the individual health condition and can therefore have a significant impact on the quality of life, both professional and private, especially when it becomes chronic [25]. Back pain as an occupation-related problem has been reported for various professions, among them are health-care providers, such as nurses and physicians of various specialties $[23,26]$. Ophthalmologists may have an essential risk profile since many procedures in their daily routine are performed in nonphysiological postures.
General ophthalmologists spend most of their time working on the slit lamp or desk or performing refractions as well as ophthalmoscopy, whereas ophthalmic surgeons work continuously for hours at the surgical microscope or using magnifying glasses. Both working profiles reveal continuous, repetitive, and identical motion sequences in awkward and prolonged cramped working postures, bending and twisting under a high cognitive demand and workload, lacking relaxation breaks for physical as well as psychological recreation (Fig. 2) [3].

The use of the slit lamp overstretches the examiner's neck and brings the upper neck joints into an extremely strong recline. This causes an abnormal burden of the cervical spine with asymmetric pressure of the intervertebral discs below and with fatigue of the neck muscles (mm suboccipitalis). This in turn causes a high pressure on nerves and vessels to the arm, the inner ear, and the head. The anteriorly directed position of the head leads to an overall nonphysiological kyphosis along the spine and an additional burden on the lumbar region, including discs, nerves, and vessels. Furthermore, partial twisting and bending movements, especially when working at the slit lamp and desk or using the phoropter, may cause a nonphysiological torsion of the cervical and lumbar 
spine, if the working sector is not adjusted. Similarly, surgeons at the microscope tend to recline the upper cervical spine and to tilt the pelvis backward with an unphysiologic kyphosis in the lumbar spine. Over time this leads to discomfort and pain in the low back and/or in the sciatic nerve.

Seidel and colleagues [27] demonstrated severely increased burdens on the spinal column, especially in the lumbar region, when working at the slit lamp (about $250 \%$ increase), performing indirect ophthalmoscopy (about 200\% increase), and using the head ophthalmoscope during indirect ophthalmoscopy (about 183\% increase).

From all questionnaires sent to the members of the BVA, only 1,861 copies (31\%) were returned. The response rate appears low but was comparable to other surveys $[1,3,7,26,28-30]$. We currently cannot judge, if the data obtained is representative for the whole community as the reasons for not sending back the questionnaire usually are manifold and include "no interest," "no time to answer," "not relevant for me," etc.

However, all ophthalmologists who took part in this survey filled the questionnaire carefully, and only 54 $(<1 \%)$ gave incomplete data. One may conclude that mainly ophthalmologists with recent and/or past acute and/or chronic back pain had answered the questionnaire and the prevalence found in this survey might be too high regarding the whole group. This makes a comparison of the current data with that from previous surveys related to MSD of the back and neck in the general population difficult [24]. Earlier investigations of the prevalence of back pain complaints in ophthalmologists showed response rates between 6 and $82 \%$ [1, 3, 7, 26, 28-30]. The fact that in 1 survey ophthalmologists replied considerably more frequently than family medicine physicians might emphasize that professions affected have per se a higher response rate [26]. In conclusion, the question if ophthalmologists suffer significantly more often from back pain complaints than other professionals or the general population cannot be answered with certainty.

The analysis of the data we received revealed a surprisingly high percentage of ophthalmologists (81\%) with current back pain complaints. This is in accordance with previous investigations that showed prevalences ranging from 33 to $93 \%$ [1, 3, 6, 7, 26, 28-30]. In comparison to the general population ophthalmologists apparently suffer from back pain complaints more frequently, as annual prevalences in the general population range between 8 and 65\% [3-15]. Our results reveal that ophthalmologists of both genders and all age-groups are more affected than the general population [24], emphasizing that ophthalmologist may have an increased risk of developing back pain complaints. This assumption is supported by data from a recent publication comparing the prevalence of back pain in ophthalmologists with family medicine physicians [26]. It was shown that eye care providers suffer significantly more from back pain complaints and risk factors like long working hours, examining many patients per day, working in continuous, repetitive, and identical motion sequences in awkward and prolonged cramped working postures (e.g., slit-lamp examinations, performing laser or surgery) can be made responsible for this observation $[3,26,30]$.

We found that older ophthalmologists were more often affected than younger ones; female ophthalmologists were affected more often than males, and females were younger. In addition, a trend toward steadily increasing back pain complaints dependent on the number of professional years was stated. Thus, older age, female gender, and number of professional years appeared to be risk factors for developing back pain complaints in German ophthalmologists. However, no significant difference was found when comparing the specific working profiles (e.g., performing either medical or surgical ophthalmology or both). The rate of reported back pain complaints varied only between 74 and $83 \%$.

The most frequently reported complaints were cervical spine discomfort (65\%), followed by lumbar spine (53\%), and shoulder (38\%) problems, yet the location of symptoms varied dependent on the working profile: those who performed conservative treatment only or to a larger extent than surgical ophthalmology mainly reported cervical spine complaints, whereas those who solely or predominantly performed surgical ophthalmology reported more symptoms in the lumbar spine region. In the general population, the leading region of back pain complaints was reported to be in the lumbar region (73\%) [13]. This indicates a specific profession-specific disease pattern in ophthalmologists.

A comparison of the current results with earlier investigations evaluating back pain complaints in ophthalmologists showed various aspects. We found increased back pain complaints in ophthalmologists at an older age whereas previous studies contrarily demonstrated increased pain in younger age-groups $[1,3,7,28,30]$. The high prevalence in the younger subgroup was attributed to a relatively heavier workload in the outpatient department, a specific working profile (e.g., performing many retinal laser procedures) and longer working hours than older colleagues $[7,30]$. Contrariwise, more inexperience 
leading to more stress for younger colleagues might be another cause that could be suspected for this observation. The younger age-group may be less adapted to this kind of work, less aware of inadequate postures, etc., and therefore, more vulnerable to spine problems [7, 28].

Furthermore, female gender was previously described to be associated with increased back pain complaints in ophthalmologists $[1,30]$ which are in accordance with our results. A higher number of professional years appeared to be associated with back pain complaints, whereas in previous investigations such an association was not found $[3,28-30]$. We could not detect a significant difference in the prevalence of back pain complaints between general ophthalmologists and ophthalmic surgeons in this series (between 74 and 83\%). Previous reports also have shown similar high prevalences between 82 and 93\% [28]. The predominant location of back pain complaints of medically working ophthalmologists was the cervical spine column and the lumbar spine region in ophthalmic surgeons. Similarly, Chatterjee and colleagues [29] reported about 34\% cervical pain and $81 \%$ lumbar pain in ophthalmic surgeons. Furthermore, they analyzed the prevalence of back pain complaints among ophthalmic subspecialties and demonstrated that general ophthalmologists suffer in about $60 \%$ of cases from back pain, followed by vitreoretinal-, glaucoma- and oculoplastic specialists. Neuro-ophthalmologists were only affected between 1 and 3\% [29]. Venkatesh and colleagues [30] demonstrated that squint- and pediatric-, neuro-ophthalmologic- and oculoplastic specialists as well as retinal surgeons had no increased risk for developing back pain complaints, whereas cataract surgeons, general ophthalmologists, cornea- and refractive surgeons, glaucoma-as well as medical retina specialists were at an increased risk. Finally, Hyer and coworkers [3] showed an overall neck pain prevalence of $30 \%$ in their investigation, primarily by vitreoretinal specialists and followed by oculoplastic-, glaucoma- and pediatric experts. Overall lumbar back pain was reported in $47 \%$, most often in general ophthalmologists and followed by glaucoma-, medical retina, and neuro-ophthalmologic colleagues [3]. We did not analyze our data accordingly because in Germany most ophthalmologists do not specialize that strictly and we adapted the questionnaire, accordingly, distinguishing between nonsurgical and surgical work focus.

In our survey, $>70 \%$ of participants link their back pain complaints to their profession and their specific working postures. Such a high correlation was also found in previous investigations $[3,6,28,30]$. Al-Marwani and colleagues [28] showed that in $89 \%$ of ophthalmologists affected back pain reduced or disappeared during holidays. Thus, it seems obvious that the chronic occupational burden in ophthalmologists may be 1 cause of the high prevalence of back pain complaints. Consequently, $>50 \%$ of all respondents in almost all age-groups exercise in their leisure time to cope with their complaints. Further therapeutic strategies were massages, physiotherapy, use of analgesics, heat application, osteopathy, yoga, and surgical interventions $[3,29,30]$. Similar behavior patterns to treat and/or prevent (chronic) back pain complaints were reported by others [31]. Physical activity in general (e.g., land-and water-based activities) as well as physical exercise focusing on building strength, endurance, flexibility, as well as muscle activation and motor control were reported to have an excellent impact on back pain complaints [25, 31]. Physical activity and physical exercise reduced the severity of pain, improved functions, and showed variable effects on psychological function and quality of life [25].

Almost $60 \%$ of all ophthalmologists interviewed in our survey postulated that an optimization of their workplace and working environment would have a positive impact on daily practice with regard to physiologic and less stressful postures. Such proposals include the correct use of ergonomic chairs and desks, adjustments of slit lamps, microscopes with respect to height and inclination of oculars, a better positioning of patients' heads during examinations and surgery $[3,30]$. Especially the introduction of 3-dimensional heads-up display surgical systems and their implementation into daily routine has made a substantial improvement in avoiding or improving back pain complaints (personal communication Profs. Koss \& Priglinger) in up to $>60 \%[32,33]$.

\section{Conclusions}

For these reasons, more awareness of this important issue must be brought into the community, especially with regard to prevention. Manufacturers of ophthalmic devices and equipment should improve the ophthalmologists' working environment, for example, 3-dimensional heads-up display surgical systems. The role of employers and the professional societies can be to implement workflows that allow microbreaks for relaxation and exercises. Physiotherapists could help on various levels: not only in the prevention, in the treatment and rehabilitation of individuals affected, but also in giving advice to the industry to develop ergonomic working places. The fact that even 
younger ophthalmologists already suffer from (chronic) back pain stresses the significance of prophylactic measures, such as specific exercise and an ergonomic working environment which is needed to maintain the ability to work and preserve the quality of life.

\section{Acknowledgements}

We thank bonoptic, Luebeck, Germany and the "Bundesverband der Augenärzte (BVA)" for their support during this investigation. We acknowledge support by the Open Access Publication Funds of the Göttingen University.

\section{Statement of Ethics}

The study adhered to the guidelines of Good Clinical Practice and adhered to the tenets of the Declaration of Helsinki. The institutional ethics committee ("Ethikkommission der Universitätsmedizin Göttingen") approved this project with reference number 40/4/20. Informed consent to participant was not directly obtained but inferred by completion of the questionnaire/participation in the questionnaire.

\section{Conflict of Interest Statement}

Thomas Bertelmann is an employee of Novartis Pharma GmbH Nuremberg, Germany and a scientific staff member of the Department of Ophthalmology, University Medical Center Goettingen, Germany. He has received funding for research and clinical trials, consulting fees, honoraria, and travel reimbursement from Alcon, Alimera Sciences, Allergan, Bayer HealthCare, and Novartis. Astrid Heutelbeck declares no conflict of interest. Silvia Bopp declares no conflict of interest. Lise-Lott Sagebiel declares no conflict of interest. Silke Eichberg declares no conflict of interest. Ernst
Hallier declares no conflict of interest. Reinhard Hilgers declares no conflict of interest. Claudia Quiering is an employee of Novartis Pharma GmbH, Nuremberg, Germany. Hans Hoerauf has received funding for research and clinical trials from Bayer Healthcare, Heidelberg Engineering, Carl Zeiss Meditec, Roche/Genentech, Ophthotech, Lutronic, Regeneron, Boehringer Ingelheim, Bioeq/Formycon, Alcon, Novartis und Allergan as well as consulting fees and honoraria from Bayer Healthcare, Alimera Sciences, Alcon, Novartis, Thrombogenics, Heidelberg Engineering, TheaPharm, and Allergan. He has shareholdings from Novartis, $3 \mathrm{M}$, Roche, Bayer, Johnson \& Johnson, Mediatronic.

\section{Funding Sources}

There was no funding source for this research project.

\section{Author Contributions}

T.B. substantially contributed to the analysis or interpretation of data for the work. He drafted the work and revised it critically for important intellectual content. A.H., S.B., L.S., S.E., E.H., and H.H. substantially contributed to the conception or design of the work, the acquisition, analysis, or interpretation of data for the work. R.H. and C.Q. substantially contributed to the conception or design of the work, analysis, or interpretation of data for the work. All authors critically revised the work for important intellectual content. Furthermore, all authors gave their final approval of the version to be published and agreed to be accountable for all aspects of the work in ensuring that questions related to the accuracy or integrity of any part of the work are appropriately investigated and resolved.

\section{Data Availability Statement}

Availability of data and materials: The datasets used and analyzed during the current study are available from the corresponding author on reasonable request.

\section{References}

1 Dhimitri KC, McGwin G, McNeal SF, Lee P, Morse PA, Patterson M, et al. Symptoms of musculoskeletal disorders in ophthalmologists. Am J Ophthalmol. 2005;139(1):17981.

2 Punnett L, Wegman DH. Work-related musculoskeletal disorders: the epidemiologic evidence and the debate. J Electromyogr Kinesiol. 2004;14(1):13-23.

3 Hyer JN, Lee RM, Chowdhury HR, Smith HB, Dhital A, Khandwala M. National survey of back \& neck pain amongst consultant ophthalmologists in the United Kingdom. Int Ophthalmol. 2015;35(6): 769-75.

4 Carey TS. Occupational back pain: issues in prevention and treatment. Baillieres Clin Rheumatol. 1989;3(1):143-56.
5 Frank A, Townsend J. Low back pain. Smoking linked to back pain. Br Med J. 1993; 306(6882):1268-9.

6 Furber A, Fanello S, Roquelaure Y, Lelevier F, Le Cardinal S, Penneau-Fontbonne D, et al. (Lower back pain in physicians. Epidemiological aspect and risk factors). Rev Rhum Mal Osteoartic. 1992;59(12):777-83.

7 Chams H, Mohammadi SF, Moayyeri A. Frequency and assortment of self-report occupational complaints among Iranian ophthalmologists: a preliminary survey. MedGenMed. 2004;6(4):1.

8 Cassou B, Derriennic F, Monfort C, Norton J, Touranchet A. Chronic neck and shoulder pain, age, and working conditions: longitudinal results from a large random sample in France. Occup Environ Med. 2002;59(8):537-44.
9 Croft PR, Papageorgiou AC, Thomas E, Macfarlane GJ, Silman AJ. Short-term physical risk factors for new episodes of low back pain. Prospective evidence from the South Manchester Back Pain Study. Spine. 1999;24(15): 1556-61.

10 Maniadakis N, Gray A. The economic burden of back pain in the UK. Pain. 2000;84(1):95103.

11 Palmer KT, Walker-Bone K, Griffin MJ, Syddall H, Pannett B, Coggon D, et al. Prevalence and occupational associations of neck pain in the British population. Scand J Work Environ Health. 2001;27(1):49-56.

12 Walker BF. The prevalence of low back pain: a systematic review of the literature from 1966 to 1998. J Spinal Disord. 2000;13(3): 205-17. 
13 BKK BV 2008. Langzeitstudie Rückenschmerzen: BKK Faktenspiegel; 2008 Nov. p. $1-4$.

14 Techniker Krankenkasse. Rückenschmerzen - Eine Information für Patienten und Angehörige. 1st ed: Arcis Verlag GmbH München/ Düsseldorf; 1997.

15 Neuhauser H, Ellert U, Ziese T. (Chronic back pain in the general population in Germany 2002-2003: prevalence and highly affected population groups). Gesundheitswesen. 2005; 67(10):685-93.

16 Statistisches Bundesamt. 1999.

17 Sjaastad O, Bakketeig LS. Tractor drivers' head- and neck-ache: vågå study of headache epidemiology. Cephalalgia. 2002;22(6):462-

18 Al Wazzan KA, Almas K, Al Shethri SE, AlQahtani MQ. Back \& neck problems among dentists and dental auxiliaries. J Contemp Dent Pract. 2001;2(3):17-30.

19 Gurgueira GP, Alexandre NM, Corrêa Filho HR. (Self-reported musculoskeletal symptoms among nursing personnel). Rev Lat Am Enfermagem. 2003;11(5):608-13.

20 Long MH, Bogossian FE, Johnston V. The prevalence of work-related neck, shoulder, and upper back musculoskeletal disorders among midwives, nurses, and physicians: a systematic review. Workplace Health Saf. 2013;61(5):223-30.
21 Al-Mohrej OA, AlShaalan NS, Al-Bani WM, Masuadi EM, Almodaimegh HS. Prevalence of musculoskeletal pain of the neck, upper extremities and lower back among dental practitioners working in Riyadh, Saudi Arabia: a cross-sectional study. BMJ Open. 2016;6(6): e011100.

22 Magnavita N, Bevilacqua L, Mirk P, Fileni A, Castellino N. Work-related musculoskeletal complaints in sonologists. J Occup Environ Med. 1999;41(11):981-8.

23 van Doorn JW. Low back disability among self-employed dentists, veterinarians, physicians and physical therapists in The Netherlands. A retrospective study over a 13-year period $(\mathrm{N}=1,119)$ and an early intervention program with 1-year follow-up $(\mathrm{N}=134)$. Acta Orthop Scand Suppl. 1995;263:1-64.

24 Robert-Koch-Institut 2006. Gesundheit in Deutschland. Gesundheitsberichterstattung des Bundes. Berlin: Robert-Koch-Institut; 2006.

25 Geneen LJ, Moore RA, Clarke C, Martin D, Colvin LA, Smith BH. Physical activity and exercise for chronic pain in adults: an overview of cochrane reviews. Cochrane Database Syst Rev. 2017;4:CD011279.

26 Kitzmann AS, Fethke NB, Baratz KH, Zimmerman MB, Hackbarth DJ, Gehrs KM. A survey study of musculoskeletal disorders among eye care physicians compared with family medicine physicians. Ophthalmology. 2012;119(2):213-20.
27 Seidel EJ, Fischer A, Seidel S, Zweiling K, Günzler W. Belastungen der Wirbelsäule bei der augenärztlichen Tätigkeit. Heft. 2005 Oct; 39(5):205-7.

28 Al-Marwani Al-Juhani M, Khandekar R, AlHarby M, Al-Hassan A, Edward DP. Neck and upper back pain among eye care professionals. Occup Med. 2015;65(9):753-7.

29 Chatterjee A, Ryan WG, Rosen ES. Back pain in ophthalmologists. Eye. 1994;8(Pt 4):473-4.

30 Venkatesh R, Kumar S. Back pain in ophthalmology: national survey of Indian ophthalmologists. Indian J Ophthalmol. 2017;65(8): 678-82.

31 Nilsen TI, Holtermann A, Mork PJ. Physical exercise, body mass index, and risk of chronic pain in the low back and neck/shoulders: longitudinal data from the Nord-Trondelag Health Study. Am J Epidemiol. 2011;174(3): 267-73.

32 Weinstock RJ, Ainslie-Garcia MH, Ferko NC Qadeer RA, Morris LP, Cheng H, et al. Comparative assessment of ergonomic experience with heads-up display and conventional surgical microscope in the operating room. Clin Ophthalmol. 2021;15:347-56

33 Bin Helayel H, Al-Mazidi S, AlAkeely A. Can the three-dimensional heads-up display improve ergonomics, surgical performance, and ophthalmology training compared to conventional microscopy? Clin Ophthalmol. 2021;15:679-86. 